recibido: 08.01 .13 / aceptado: 12.03 .13

\title{
La participación de los oyentes en las radio APPs españolas. Prácticas convencionales en la era de la portabilidad.
}

\author{
Teresa Piñeiro-Otero \\ Universidade da Coruña \\ José Juan Videla Rodríguez \\ Universidade da Coruña
}

\section{Palabras clave}

Radio online, mediamorfosis, radiofonía móvil, aplicaciones, cultura de la portabilidad, cuarta pantalla.

\section{Resumen}

El traspaso de la radiofonía hertziana a la Internet ha supuesto una transformación radical del medio sonoro. Con la mediamorfosis la radio ha perdido algunas de sus características clásicas como su fugacidad y su esencia exclusivamente sonora, al tiempo que ha estrechado la relación con su audiencia por medio de la adopción de nuevas formas de participación basadas en la interactividad.

En el contexto de la cultura de la portabilidad, la radiofonía online consolida su presencia en diversos dispositivos portátiles. La radiofonía móvil va más allá de una nueva plataforma de distribución; supone una nueva dimensión de la radiomorfosis que exige la creación de contenidos radiofónicos adecuados a estos receptores inteligentes.

La mutiplicación de terminales portátiles junto a la penetración alcanzada por la banda ancha móvil han propiciado la aparición del usuario conectado; usuario que presenta enormes potencialides para el medio sonor. En este sentido, el presente estudio ha tenido por objeto conocer la oferta de las aplicaciones para tablet y smartphone de las cadenas españolas, así como las posibilidades de participación que dichas APP ponen a disposición de los oyentes-usuarios. 
The participation of the audience in the Spanish radio apps.

Conventional practices in the era of portability.

\title{
Keywords
}

Online radio, mediamorphose, mobile radio broadcast, aplications, portable culture, fourth screen.

\begin{abstract}
Change of hertz radio broadcast into Internet has supposed a radical transformation to the sound media. With the mediamorphose, radio has lost some of its classic characteristics like fugacity and its audible essence, and the exclusively sound essence at the same time the time that radio has strength its relation with its audience trough new participation forms based in the interactiveness.

At the portability culture, online radio consolidates its presence in portable devices. Mobile radio goes further of a new distribution platform; it's a new radiomorphose dimension that demands content optimized to these intelligent receptors.

Portable terminals multiplication and mobile broadband penetration had evolved into a new user: the connected user; whom presents several potentials to sound media. Present study aims to know tablet \& smartphones applications offer at Spanish radio channels, and these APPs listeners-users participation possibilities.
\end{abstract}

\section{Autor}

Dra. Teresa Piñeiro-Otero [teresa.pineiro@udc.es] y Dr. José Juan Videla Rodríguez [videla@udc.es] 


\section{Introducción}

El traspaso de la radiofonía hertziana a Internet, la llamada mediamorfosis de la radio (Fidler, 1997), ha supuesto una revolución completa del medio sonoro. Este proceso, para el que Prata (2008) acuñó el término radiomofosis, no ha constituido una simple transferencia de contenidos de las ondas a la Web (Faus, 2001), sino que ha implicado una redimensión del producto sonoro con la incorporación de nuevas potencialidades inherentes al sistema digital.

En la Red, el medio radiofónico ha dado lugar a una plataforma donde los mensajes de audio convergen con otros contenidos de carácter textual, hipertextual y mutimedia. Con la construcción y transmisión de este nuevo mensaje, la radio semeja haber perdido su vocación sonora (Barreiro Lima, 2001), pero no ha sido así. El sonido continúa siendo el elemento esencial de la radiofonía online; un sonido que debe estar dotado de sentido completo con independencia de los elementos multimedia que lo acompañen (Prata, 2008).

La radio online, neorradio, radionet, Internet only, radio virtuale, iRadio, bitcaster, ciberradio o webradio perfila nuevos usos, diversas formas de producción y distribución de contenidos que han implicado la aparición de un nuevo rol de oyente-usuario (Rivadeneyra, 2008: 240).

Más allá de la forma de emisión clásica, en streamming, la radiofonía online incorpora nuevos modos de consumo bajo demanda que admiten la creación de una radio a medida del oyente-usuario. Frente a la fugacidad característica de la radiofonía hertziana, la radio en Internet permite conservar lo difundido de forma íntegra, fragmentada o selectiva, durante un período de tiempo más o menos amplio, posibilitando un consumo diacrónico (Cebrián Herreros, 2008a).

La disponibilidad de contenidos en archivos online, especialmente en formato podcast, permite a la radio en Internet flexibilizar la experiencia del radioyente (Paz, 2007). Esta potencialidad del medio radiofónico online constituye, junto a la personalización de contenidos, una de las principales bazas para la fidelización de oyentes virtuales (Bufaran y Casper, 2010; Pacheco, s/f).

Asimismo, la radio en Internet ha permitido estrechar la relación con sus oyentes a través de nuevos modos de interacción más próximos e instantáneos, como las redes sociales, que han logrado horizontalizar la comunicación entre emisora y oyentes. Los social media han redimensionado el concepto de participación de la audiencia radiofónica; ya no se puede hablar de productores y consumidores como papeles separados, sino que interactúan en función de nuevas reglas (Jenkins, 2006; Moreno et al., 2009).

En este contexto resulta preciso hacer referencia a la eclosión de la self-communication (Merayo, 2001: 290) como contraposición a los medios de comunicación de masas; surgimiento que se ha visto influenciado por la cultura de la portabilidad, que marca el inicio de una nueva etapa. En el medio sonoro esta etapa ha implicado la conjunción de modalidades de recepción ya consolidadas 
con nuevas formas de interacción que, como subraya Kischinhevsky (2009: 230) han provocado cambios relevantes en el proceso de comunicación.

Al seleccionar una determinada emisora online, al usuario se le abren múltiples posibilidades, impensables en el medio convencional, entre las que Cebrián Herreros $(2001,112-113)$ destaca el acceso a los contenidos programáticos siempre y en cualquier lugar, la facilidad de compartirlos con otros usuarios durante su consumo o en un tiempo diferente al mismo, y el hecho de poder efectuar comentarios, formular preguntas, aportar datos e intercambiar opiniones sobre dichos contenidos.

El medio surgido a partir de la radiomorfosis ha ampliado sus estrategias comunicativas más allá del ámbito estrictamente sonoro (González Conde, 2010), ha perdido fugacidad (Priestman, 2001) lo que ha llevado al desarrollo de un nuevo concepto de programación a medida del usuario (Albarran y Pitts, 2001), ha incorporado nuevas formas de participación más interactivas (Priestman, 2002,; Tolson, 2006; Nyre y Ala-Fossi, 2008) que se han reflejado en la creación de comunidades de oyentes más cohesionadas y segmentadas (Priestman, 2001: 226).

Desde una perspectiva social, el proceso de radiomorfosis ha dado mayor proyección a elementos distintivos del medio convencional como su portabilidad y la posibilidad de un consumo multitasking. Como señalan Vieira et al. (2010) las nuevas manifestaciones de la radio permiten su disfrute al mismo tiempo que se consumen otros contenidos o se desarrollan otras tareas, posibilitando la yuxtaposición con otros medios y un uso multicontexto (online y offline, móvil o fijo).

Las potencialidades de este consumo multitasking no sólo convierten a la radio en un medio privilegiado (Bufarah Junior, 2003) sino que configuran una oportunidad única para su expansión en el marco de la cultura de la portabilidad.

\section{Radiofonía móvil}

En un contexto caracterizado por la convergencia de contenidos y de pantallas, la telefonía móvil (Castells et al., 2006) y los dispositivos portátiles de altas prestaciones constituyen las nuevas plataformas de expansión de la radiofonía online.

Si bien la transistorización de la radio permitió la recepción del medio hertziano en dispositivos inalámbricos de diversa índole, inclusive en terminales telefónicos, no se puede hablar de radiofonía móvil hasta el inicio de la experimentación del medio sonoro con la telefonía móvil, hace más de una década (Vacas, 2007).

La radiofonía móvil no constituye simplemente la suma de dos tecnologías -radio y telefonía móvil, o cualquier otro receptor inalámbrico- sino que supone la adecuación del mensaje sonoro a una plataforma con nuevas potencialidades, servicios y contenidos (Cebrián Herreros, 2008b). En este sentido, referirse a la 
radiofonía móvil es hacerlo de una dimensión de la radiomorfosis estrechamente ligada a la cultura de la portabilidad.

Siguiendo a Cebrián Hereros (2008b), en el momento actual la radiofonía móvil se encuentra en la tercera etapa, en la que se produce una plena convergencia técnica-comunicativa que permite el acceso desde los dispositivos portátiles a todos los contenidos de la radio en Internet. En esta etapa la radiofonía móvil también ha ampliado su catálogo de receptores, de los terminales telefónicos a todo un conjunto de dispositivos portátiles. Se puede consumir contenidos radiofónicos en reproductores multimedia, smartphones, tablets así como otro tipo de receptores digitales (Del Bianco, 2011).

Además de la multiplicación de plataformas receptoras, la extensión de la radiofonía móvil a nuevos terminales inalámbricos de altas prestaciones ha resultado positiva en términos de conectividad ya accesibilidad, lo que ha implicado una verdadera revolución en el acceso y disfrute de los contenidos radiofónicos. Esta revolución, que Kishinevsky (2009) asocia a la cultura de la portabilidad, se caracteriza por la aparición y democratización de una serie de terminales móviles de altas prestaciones (especialmente smartphones y tablets) que operan con sencillas extensiones de software, las aplicaciones o APP, para un acceso optimizado a diversos servicios web.

El lanzamiento del iPhone en 2007 y del iPad en 2010, ha constituido una auténtica revolución tanto en el ámbito de los mobile devices como en el del mobile computing. La exponencial penetración alcanzada por tablets y smartphones, con un incremento del $296 \%$ y un $74 \%$ en el último año (La sociedad de la Información en España, 2011), ha llevado a diversos medios de comunicación a crear sus aplicaciones ex profeso para dichos dispositivos.

En este sentido Gallego (2010), señala que son diversas las emisoras españolas que han considerado interesante el lanzamiento de aplicaciones para el disfrute de contenidos radiofónicos desde múltiples sistemas operativos móviles, especialmente en lo que respecta a los más generalizados: Android e iOS.

La radio móvil o, como la denomina Cebrián Herreros (2008b), la ciberradio móvil o en movilidad exige un rediseño de las aplicaciones o -si fuese el casode la web móvil para un acceso optimizado desde múltiples dispositivos portátiles. Como señala The Horizont Report 2012, las mejores APP son aquellas que se adaptan completamente a las potencialidades del dispositivo, utilizando datos de posicionamiento, detención de movimiento, acceso a redes sociales o búsqueda web -entre otros- en una experiencia completamente integrada. Se trata de un extenso universo de servicios que convergen en la palma de la mano (Padley, 2012).

La confluencia de servicios que caracteriza la radio móvil ha dado lugar a un nuevo perfil de consumidor de Radio 3.0, un consumidor que descarga la aplicación de su emisora preferida para disfrutarla con un solo clic (Ortiz Sobrino, 2012). 


\section{Una nueva relación con el usuario}

La rápida evolución de los dispositivos móviles ha estimulado el desarrollo de soluciones multiplataforma para la distribución de contenidos radiofónicos, y con éstas la aparición de una audiencia -cada vez más amplia- de radio en movilidad. Según el informe Radio: Tradicional vs. online de la AIMC (2012) alrededor del $18 \%$ de los usuarios de radio online ya utilizan el teléfono móvil como plataforma principal de acceso y un $12 \%$ lo hacen desde tablets.

Las potencialidades que ofrecen los dispositivos portátiles de altas prestaciones, en especial las tablets y los stmarpthones, no sólo han repercutido de forma positiva en la audiencia de la radio móvil, sino que han logrado crear una comunidad de oyentes-usuarios permanentemente conectados.

Con su transposición a la Internet, la radio ha logrado estrechar la relación con sus oyentes a través de nuevas formas de participación basadas en la interactividad (Priestman, 2002; Tolson, 2006; Nyre y Ala-Fossi, 2008), al frente de las cuáles se sitúan las redes sociales. Estas plataformas 2.0 cobran relevancia en el ámbito de la radio en movilidad dada la posibilidad que brindan los dispositivos portátiles de interactuar con el medio en cualquier momento en cualquier lugar.

Frente a la participación radiofónica clásica, a la que Herrera (2004) confiere categoría de género radiofónico, los nuevos canales de interacción surgidos de la mediamorfosis incrementan la capacidad expresiva e innovadora del medio, al tiempo que estimulan la aparición del oyente interactivo. «Nacen géneros interactivos diferentes a los tradicionales dialógicos como los audiochats, audioforos, audioconferencias. El diálogo interactivo supera también al diálogo interpersonal directo. Los productos finales que hasta ahora se consideraban cerrados por parte de los productores quedan abiertos para que los usuarios incorporen otros elementos» (Cebrián Herreros, 2009: 17).

La naturaleza de la Red y de sus herramientas de interacción social ha permitido traspasar los límites establecidos entre la radio y sus oyentes. En efecto, la radiofonía online, tanto en su manifestación web como en móvil, confiere un mayor protagonismo al oyente que, como afirman González Conde y Salgado Santamaría (2009), asume el rol de administrador de contenidos.

Se trata de una nueva generación de receptores cuyas características diferenciales respecto de la anterior hacen precisa una nueva denominación. Cebrián Herreros habla de un usuario-oyente, denominación que fue adaptada para este trabajo. Primo (citado en Kischinhevsky, 2007) se refiere a «interagentes», expresión que presupone una relación entre individuos y entre éstos y las máquinas que gestionan las nuevas herramientas comunicativas. Este término resulta más próximo al de «prosumidor», entendido como paradigma del usuario que toma parte activa en el proceso de creación de contenidos mediáticos.

Las emisoras radiofónicas, conscientes de la interactividad técnica y comunicativa que ofrece la Red, han definido espacios propios para guiar al usuario en las 
acciones que debe realizar, al tiempo que incrementan la presencia de herramientas y servicios interactivos (González Conde y Salgado Santamaría, 2009: 51). Esta redefinición de los servicios ofertados está profundamente marcada por el hecho de que, como subraya Moares (citado en Buffarah Junior, 2004: 6), en Internet no hay lugar para receptores pasivos.

La radio después de la mediamorfosis incrementa las posibilidades de intervención de sus oyentes-usuarios, que no se limitan únicamente a la participación en el contenido emitido sino en la personalización de la programación, el orden de recepción e -inclusive- el diseño del medio.

En este sentido, Tolson, en su obra Media talk. Spoken discourse on TV and radio (2006), desarrolla una propuesta de análisis de la participación de los oyentes-usuarios en las radios online que incorpora estas dos perspectivas: la intervención en los contenidos del medio (interacción pública) y en la personalización de su recepción (interacción de carácter privado). En función de dichas perspectivas, Tolson señala hasta nueve posibilidades de intervención de los usuarios en los contenidos vehiculados por el medio radiofónico.

Si se atiende a la posibilidad de participación de los oyentes-usuarios en aquellos contenidos que el medio radiofónico vehicula, Tolson señala los siguientes ítems:

- Los usuarios producen su propio discurso y material audiovisual y lo publican sin acuerdo previo con los proveedores del servicio. Esta posibilidad de participación, que Tolson considera como la más activa, adquiere especial relevancia en el ámbito de la radiofonía móvil. Los smartphones y tablets ya incorporan tanto grabadoras como software de edición rápida.

- Los usuarios salen a la búsqueda de localizaciones geográficas concretas para interactuar con los editores del medio. Esta práctica, que todavía resulta poco frecuente en el ámbito de la radio española, está basada en la utilización de servicios de localización GPS para interactuar con los gestores del medio durante la emisión de un programa. Es en esta posibilidad de participación donde la radiofonía móvil presenta una mayor ventaja competitiva respecto a la Web. Los dispositivos móviles de altas prestaciones integran aplicaciones de geolocalización que, sumadas a la posibilidad de un consumo en movimiento permiten que la interacción emisora-usuario se produzca durante la emisión del programa.

- El usuario habla o canta en el aire, en directo o pregrabado. Es una forma tradicional de participación completamente controlada por el equipo editorial, que en la radiofonía móvil se puede llevar a cabo directamente desde el propio terminal receptor (smartphones).

- El usuario escribe mensajes que son mostrados en la pantalla o leídos en el aire. Una forma de participación que presenta un mayor control del equipo editorial (más que las intervenciones orales) y que -igualmente- se puede efectuar desde los propios dispositivos receptores. Tablets y smartphones 
permiten la remisión de textos a través de servicios de mensajería como Whatsapp, Line o Skype o directamente desde las redes sociales.

En lo que respecta al segundo tipo de participación de los oyentes-usuarios en el medio, la de la oportunidad de personalizar dichos contenidos para su consumo individual, Tolson se refiere a:

- El usuario puede personalizar playlist y tener el control de la música y/o contenidos que quiere escuchar.

- Los oyentes pueden acceder a información de contexto en Internet, que supone un valor añadido a la experiencia radiofónica.

- Los usuarios pueden controlar y cambiar el tiempo de emisión de los programas. circunstancia que facilita su consumo.

- Los usuarios pueden cambiar las estaciones de radio de un conjunto de opciones. Otra vez pueden controlar qué oyen, pero no pueden seleccionar los contenidos de dicha emisora de radio.

- En la plataforma los usuarios pueden activar o desactivar la escucha de la emisión de un modo básico, sin que ello implique activar el procedimiento de inscripción.

Frente a las posibilidades de participación en los contenidos del medio, en los que la radiofonía móvil aportaba mayor valor añadido respecto a la Web, las posibilidades de personalización del consumo radiofónico son similares en ambos casos, no en vano ambas son dos perspectivas de la radio online.

La herramienta de análisis propuesta por Tolson (2006) se fundamenta en el hecho de que el acto de habla supone el modo más potente de participación en la radio, de modo que todas las posibilidades de intervención que brindan las plataformas radiofónicas deben reevaluarse en función de éste. Un tipo de participación que ha incrementado sus potencialidades en el contexto de la cultura de la portabilidad.

\section{Objeto e hipótesis de trabajo}

El presente trabajo forma parte de una investigación más amplia sobre la adaptación de las cadenas de radio de mayor audiencia en España a la nueva dimensión de la radiomorfosis: la radiofonía móvil. La adaptación de estas cadenas a la distribución de sus contenidos a través de los dispositivos móviles de altas prestaciones puede enfocarse desde dos perspectivas diferentes y no excluyentes: la creación de mobile webs mejoradas para su consulta en la llamada cuarta pantalla o la disposición de APP que permitan un acceso optimizado desde dichos terminales. 
Tal como recoge el Informe de la Sociedad de la Información en España (2012), en el año 2011 la banda ancha móvil en España superó en número de líneas a la banda ancha fija, alcanzando una ratio de 29,7 conexiones para dispositivos portátiles por cada 100 habitantes. El exponencial crecimiento de la banda ancha móvil supone un indicador del cambio de hábitos de consumo de contenidos en España. El propio terminal telefónico está dejando atrás su función original para convertirse en un dispositivo de consumo de contenidos multimedia.

En este contexto, las aplicaciones ya superan en uso a funciones clásicas de la telefonía móvil como las llamadas o el envío de mensajes. Del tiempo que dedica un usuario medio a la interacción con el teléfono móvil, las APP suponen el 47\% del tiempo total frente al $32 \%$ que ocupa en funciones convencionales (Informe de la Sociedad de la Información en España, 2012).

En este sentido, el objeto del presente trabajo ha sido el de conocer en qué medida las cadenas radiofónicas españolas están adaptando su distribución de contenidos a las nuevas formas de recepción en movilidad. En particular, qué posibilidades de participación prevén dichas emisoras de radio en sus aplicaciones para tablet y smartphone.

La hipótesis de partida es que, si bien las radios españolas han puesto a disposición de sus oyentes-usuarios APP para el acceso optimizado a sus contenidos desde iPhone, iPad, smartphone y tablet Android, las posibilidades de intervención que brindan a los oyentes-usuarios no explotan adecuadamente las potencialidades que estos dispositivos brindan para la participación en el medio sonoro.

\section{Metodología}

Con la intención de conocer las aplicaciones de las cadenas de radio españolas para el acceso a sus contenidos a través de tablet y smartphone, así como las posibilidades de participación que dichas APP brindan a sus oyentes-usuarios se ha llevado a cabo un estudio en dos etapas, cada una de ellas con unos objetivos, metodología y muestra diferentes.

En la primera etapa, dirigida a analizar la implantación de la radiofonía móvil en España, se optó por una metodología cuantitativa simple a partir de una ficha de estudio compuesta por cuatro variables en función de la oferta de APP para iPhone, iPad, smartphone Android o tablet Android.

Para dicha etapa se tomó como muestra de análisis aquellas emisoras españolas de mayor audiencia, entre generalistas y temáticas, atendiendo al segundo año móvil del Estudio General de Medios (en adelante EGM). Dicho estudio recoge los datos de audiencia de las principales cadenas españolas en el período entre octubre de 2011 y mayo de 2012 diferenciando, por una parte, entre radios generalistas y especializadas y, por otra, entre oyentes de lunes a viernes y los de 
sábado y domingo (la separación de estas franjas apenas tiene incidencia en las cadenas de mayor audiencia).

La muestra de partida estuvo compuesta por un total de 36 emisoras (13 generalistas y 23 temáticas) a las que se ha sumado $\mathrm{ABC}$ Punto Radio (lo que supone un total de 14 radios generalistas). Esta incorporación se debe a la relevancia de esta emisora generalista de ámbito estatal que, debido a su reciente creación (octubre de 2011), no ha sido incorporada a la muestra de emisoras estudiadas por el EGM hasta el tercer año móvil de 2012 (publicado el 29 noviembre en http://www.aimc.es/Entrega-de-resultados-EGM-3\%C2\%AA-ola,1181.html).

Tabla 1. Emisoras de radio con mayor número de oyentes (EGM $2^{\circ}$ oleada de 2012)

\begin{tabular}{|c|cc|}
\hline RADIOS GENERALISTAS & \multicolumn{2}{|c|}{ RADIOS TEMÁTICAS } \\
\hline SER & C40 & Rock FM \\
\hline Onda Cero & Dial & Flaixbac \\
\hline RNE & Europa FM & Rac 105 \\
\hline COPE & C100 & Intereconomia \\
\hline Rac 1 & KissFM & Hit FM \\
\hline Catalunya Radio & Máxima FM & Radio Clásica RNE \\
\hline Canal Sur Radio & Radio Marca & Catalunya Informació \\
\hline EsRadio & M80 & Euskadi Gaztea \\
\hline Radio Euskadi & Radio Olé & Onda Melodia \\
\hline Radio Galega & Flaix & Cadena Top \\
\hline Radio 9 & Rne R3 & \\
\hline Euskadi Irratia & Canal Fiesta Radio & \\
\hline Onda FM & R5tn & \\
\hline
\end{tabular}

Fuente: Elaboración propia.

En la segunda etapa de la investigación se efectuó una aproximación a las posibilidades que las APP de radio españolas brindan para la participación de sus oyentes-usuarios. Para ello se optó por la utilización de una ficha de trabajo de elaboración propia, a partir de las variables de estudio propuestas por Tolson en su obra Media talk. Spoken discourse on TV and radio (2006). Precisamente, tomando como referencia dicho estudio se ha considerado la participación desde dos perspectivas: por un lado, como posibilidad de intervención de los usuarios en los contenidos que el medio vehicula, y por otro, entendida como la oportunidad de personalizar el consumo del medio.

Para analizar primer tipo de participación se incluyeron los siguientes ítems:

- La incorporación de contenidos producidos por los propios usuarios.

- La APP permite el acceso a las redes sociales de la cadena, tanto a través de un link como de la integración de un/unos plug in de dicha red social en su interfaz.

- La participación a través de servicios de geolocalización para la interacción con los productores del medio.

- La APP permite el envío de mensajes a los productores del medio. 
En lo que se refiere al segundo tipo de intervención, el de la personalización de contenidos y disposición de los mismos para su consumo, se han establecido los siguientes ítems.

- Los usuarios pueden controlar y cambiar el tiempo de emisión de los programas, facilitando su consumo.

- Los usuarios pueden personalizar playlist de música y contenidos.

- Los usuarios pueden cambiar las estaciones de radio, seleccionado entre un conjunto de opciones.

- El usuario puede definir su posición geográfica para poder acceder a contenidos de tipo local de su interés.

- Los oyentes pueden acceder a información de contexto en Internet; información que supone un valor añadido a la experiencia radiofónica. Del mismo modo sucede en el caso del consumo de dichos contenidos, la ausencia generalizada de información contextual que acompañe al mensaje sonoro -solamente presente en 9 de las APP de la muestra- limita la posibilidad de selección del usuario entre un consumo simple (sólo el audio) o más complejo (a través de información multimedia hipervinculada).

- En la plataforma los usuarios pueden activar o desactivar la escucha de la emisión de un modo básico.

Esta herramienta se ha orientado al objeto concreto de estudio, las radio APP, así como a las posibilidades de intervención (pública en los contenidos del medio, o para el consumo en privado) que brindan los dispositivos receptores de altas prestaciones.

En este sentido, para la segunda parte del trabajo se ha concretado la selección muestral a aquellas emisoras de la muestra inicial que contasen con aplicaciones para su acceso desde terminales portátiles iOs y/o Android. Esta selección estuvo compuesta por un total de 34 emisoras con oferta de aplicación para iPhone (92\% de la muestra inicial) y 14 emisoras que cuentan con APP para iPad $(38 \%$ de la muestra inicial).

\section{Gráf. 1. Emisoras con APP en función del sistema operativo/dispositivo (\%)}

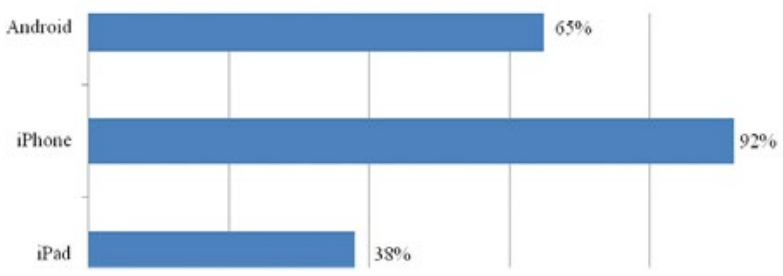

Fuente: Elaboración propia. 
En lo que respecta a las aplicaciones para Android, la ausencia de divergencias entre las APP diseñadas para su consumo en smartphone y tablet (vinculada con la limitada penetración de tablets con dicho sistema operativo y la diferencia de formatos entre fabricantes, que impide la creación de APP ad hoc como en el iPad) ha llevado a desarrollar un estudio conjunto. En concreto, la muestra de emisoras que ofertan APP para su acceso optimizado desde dispositivos Android es de 24 radios (64,8\% de la muestra inicial).

\section{Gráf.2. Radio APP en función del tipo de emisora (Generalista o especializada).}

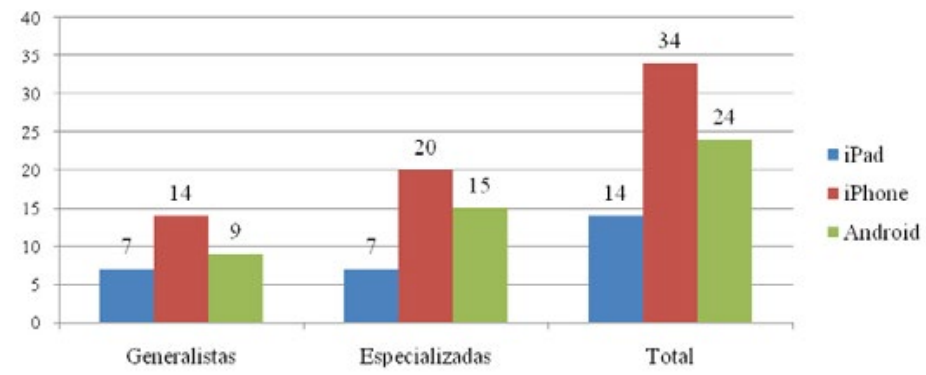

Fuente: Elaboración propia.

En esta segunda muestra, compuesta por las aplicaciones para sistemas operativos iOS y Android que las cadenas de radio de mayor audiencia ponen a disposición de sus oyentes usuarios, es preciso destacar la existencia de APP individuales y colectivas. Frente a la mayoría de las aplicaciones de las cadenas de radio privadas que han optado por el desarrollo de una oferta de carácter unitario, con independencia de su pertenencia a grandes grupos mediáticos, las cadenas de titularidad pública han integrado su oferta de contenidos para dispositivos móviles en las APP de los entes de radiotelevisión a los que pertenecen.

Es el caso -por ejemplo- de las emisoras de Radio Nacional de España, Radio Euskadi y Euskadi Irratia, de Radio Galega, Canal Sur Radio, Canal 9 (solo con APP para iPhone) etc. todas ellas pertenecientes a corporaciones públicas de radiotelevisión de carácter estatal o autonómico.

Por su parte, frente a la oferta de las cadenas privadas de ofertar APP individuales aún entre emisoras del mismo grupo (es el caso de Cadena Ser, Cadena 40, M80), existen casos de aplicaciones colectivas de grupos mediáticos privados como el de Radio Marca (un apartado dentro de la APP de Marca) o Intereconomía radio (que supone un enlace en la APP de dicho grupo mediático.

\section{Un paso hacia la radiofonía móvil}

El establecimiento de una segunda muestra de trabajo con las cadenas radiofónicas que han ofertado APP para un acceso optimizado a sus contenidos desde 
tablets y smartphones, ha adelantado algunos resultados del presente trabajo en el apartado de metodología.

En este sentido, si bien se ha señalado una desigual oferta de APP en función del sistema operativo y el dispositivo receptor, se puede señalar que el $92 \%$ de las cadenas de radio españolas de mayor audiencia (el 100\% de las emisoras generalistas y el $87 \%$ de las temáticas) ponen a disposición de sus oyentesusuarios aplicaciones para un acceso optimizado desde iPhone, iPad o cualquier dispositivo Android.

El lanzamiento del iPhone, desde la perspectiva de sus prestaciones y su concepto de pantalla, supuso una transformación tanto del mercado de terminales móviles como el de los contenidos mediáticos. La popularidad alcanzada por este smartphone le llevó a protagonizar el salto a la cuarta pantalla de numerosas empresas mediáticas, entre ellas las radiofónicas. En efecto, como se puede observar en el gráfico precedente, la totalidad de las emisoras generalistas analizadas cuentan con APP para iPhone; una circunstancia que es común al 87\% de las radios especializadas.

Gráf.3. Emisoras con APP en función de su tipología y el sistema operativo/dispositivo (\%)

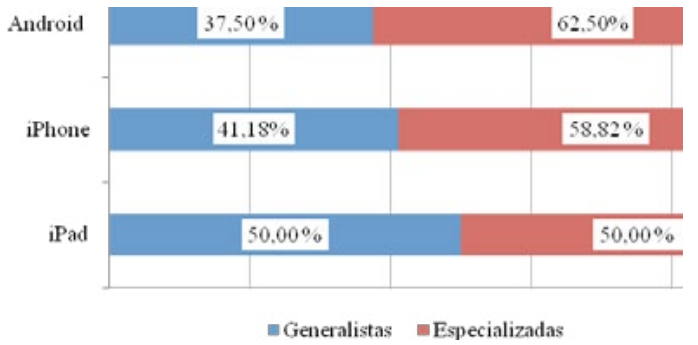

Fuente: Elaboración propia.

La oferta de radio APP es menor en el caso del iPad. Solamente el 38\% de las emisoras de la muestra han puesto a disposición de su público aplicaciones para el acceso optimizado desde este dispositivo. En lo que se refiere a su tipología, de las 14 emisoras generalistas analizadas en el presente estudio se ha constado que el 50\% de éstas ( 7 unidades) cuentan con aplicaciones ad hoc para iPad; circunstancia que se repite en el caso del $30 \%$ de las radios especializadas.

Finalmente, si atendemos a los dispositivos Android, la ausencia de un estándar de pantalla como sucedía en el caso de iOS (pese a la mayor implantación de tablets y smartphones Samsung), ha limitado la oferta de aplicaciones para este sistema operativo. En efecto, solamente el $64 \%$ de las emisoras de radio generalistas, cuentan con una APP para su acceso desde dispositivos con sistema operativo Android, mientras que en las temáticas dicho porcentaje ascienda hasta el $65 \%$ de la muestra. Esta oferta resulta limitada si se atiende al $87 \%$ 
de radios temáticas que cuentan con una aplicación optimizada para su acceso desde el smartphone de Apple.

En lo que se refiere a las emisoras de radio de gestión pública resulta destacable que todas ellas, con la excepción de la APP de iPhone de Catalunya Informació, permiten acceder a su programación a través de la aplicación colectiva de la corporación de radiotelevisión a la que pertenecen, con una oferta de contenidos conjunta. Esta práctica resulta común a una emisora privada, Intereconomía Radio cuyo acceso a los contenidos en iPhone desarrolla a través de una APP del grupo mediático que pertenece.

\section{Participación convencional en la era de la portabilidad}

La participación radiofónica, entendida desde una perspectiva clásica, hace referencia a las diversas formas de intervención del público en los contenidos del medio. La concepción que cada emisora tiene de la participación de sus oyentes va a reflejarse en los canales que dichas radios disponen para la intervención de su audiencia en sus contenidos.

Con independencia de su importancia en el contexto de la programación, se han analizado diversas posibilidades de participación en función de las ofertadas por los dispositivos móviles.

En primer lugar, la incorporación de contenidos producidos por los propios usuarios, que se perfilaba como una de las potencialidades de la radiofonía móvil apenas tiene presencia en la muestra analizada. Solamente las aplicaciones para iPhone de Rac 1 y Rac 105, y la APP de Catalunya Informació en el iPad incorporan contenidos creados por los oyentes-usuarios.

La escasa presencia de esta forma de participación, que Tolson (2008) consideró de mayor rango, implica una infrautilización de las herramientas de grabación y edición de los nuevos dispositivos portátiles.

\section{Gráf.4. APP de radio que permiten la participación de los oyentes en los contenidos del medio}

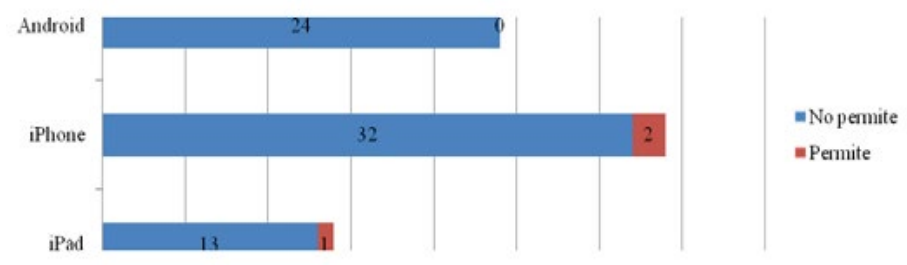

Fuente: Elaboración propia. 
Esta circunstancia se hace igualmente patente en la participación a través de las redes sociales de la emisora. El estudio llevado a cabo ha permitido constar la inexistencia de radio APP para smartphone o tablet (iOs o Android) que cuente con algún tipo de plug in social integrado en su interfaz. A pesar de que la interacción en redes sociales supone ya el $50 \%$ del tiempo que un usuario medio dedica al teléfono móvil (La sociedad de la Información en España, 2012), las APP de la muestra no presentan enlaces directos a las redes sociales.

Para poder participar en los contenidos a través de los social media, el oyenteusuario debe acceder a la Web de la cadena y -desde allí- a la plataforma social (acceso que es posible desde la propia APP en menos de una cuarta parte de los casos), o llegar al canal de la emisora desde las aplicaciones de las propias redes sociales (fuera de la radio APP). Este acceso no directo dificulta el proceso de interacción y por tanto la participación de los oyentes-usuarios móviles través de las redes sociales.

La ausencia de enlaces directos con las redes supone un límite para la expansión de la radiofonía móvil dada la pérdida de una de sus principales bazas: el usuario conectado.

Del mismo modo sucede en el caso de la participación a través de herramientas de geolocalización. Frente a las posibilidades que presentan los dispositivos portátiles para el desarrollo de aplicaciones que permitan el reconocimiento instantáneo de la posición y pese a la relevancia adquirida por algunos social media basados en la localización GPS, como FourSquare, los productores del medio todavía no han sabido sacar partido de esta oportunidad en la radiofonía móvil.

\section{Personalización de los contenidos sin características avanzadas}

Si el primer tipo de intervención en los contenidos se consideraba como el modo clásico de participación radiofónica, la personalización de dichos contenidos y su disposición personalizada para su consumo se considera uno de los elementos clave de la mediamorfosis.

En su adaptación a los dispositivos portátiles el medio radiofónico ha incorporado características de las webradios como su forma de distribución de contenidos. La radiofonía móvil permite, además de la emisión en directo, la posibilidad de un acceso bajo demanda. Esta posibilidad libera a la radio de la fugacidad a la que estaba sujeta con la creación de un repositorio, de mayor o menor envergadura, que va a permitir a los oyentes-usuarios controlar y cambiar el tiempo de emisión creando una programación personalizada.

No obstante, frente al $91 \%$ de las aplicaciones que permiten acceder a la programación en directo (88\% de las APP para iPhone, el $86 \%$ de las de iPad y el $100 \%$ de las de Android), solamente un 48\% (42\% de las APP para iPhone, 
47\% para iPad y $45 \%$ de las de Android) de la oferta contempla la posibilidad de una radio a la carta.

\section{Gráf.5. Acceso a los contenidos previsto por las radio APP en función del sistema operativo/dispositivo(\%)}

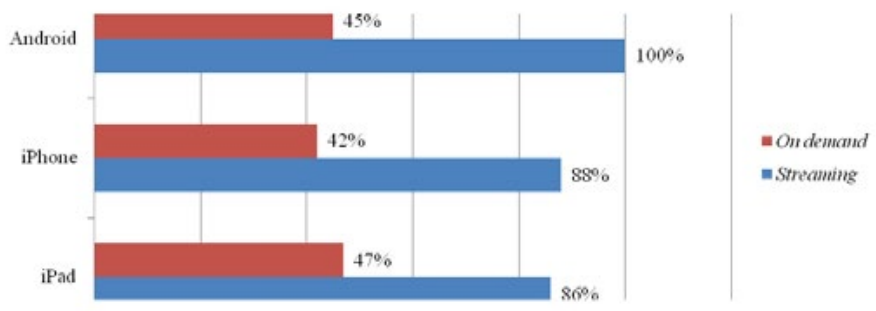

Fuente: Elaboración propia

La escasa presencia de APP que permiten un consumo de contenidos radiofónicos bajo demanda adelanta, en cierta forma, los resultados del siguiente ítem analizado: la personalización de playlist de música y contenidos.

La sencillez que presentan las aplicaciones de las cadenas de radio españolas se refleja en la personalización de la programación. En la mayoría de los casos solamente se permite el acceso aleatorio y puntual a contenidos concretos. De hecho, únicamente la APP para iPhone de la Cadena Ser ofrece la posibilidad de crear un playlist de contenidos.

En lo que respecta a la existencia de radio APP que permitan el cambio de una estación de radio a otra sin que ello implique salir de la interfaz de la aplicación, dicha opción solamente está disponible en la APP de Radio Nacional de España. Dicha aplicación limita esta selección a la programación en directo de las emisoras de radio pertenecientes a RNE.

Otros casos que podrían considerarse derivados de éste son los de los entes públicos de radio televisión del País Vasco, Cataluña y Galicia, que permiten el traspaso entre emisoras radiofónicas y canales televisivos sin por ello tener que cerrar la aplicación colectiva.

Si se atiende a la inclusión de información contextual para enriquecer la experiencia sonora, existen escasos ejemplos de APP que cuenten con información textual, hipertextual, imagética o audiovisual que dote de valor añadido a los contenidos radiofónicos. Solamente las APP de Catalunya Informació, Rac105, Cadena 40, Cadena Dial, M80 y Máxima FM para iPhone, de RNE y Rac1 para iPad y de Cadena Ser para Android, se aprovechan de las potencialidades de la radiofonía online para ofrecer una experiencia enriquecida a sus oyentes. 
Las posibilidades de geolocalización que brindan los dispositivos móviles de última generación tampoco son aprovechadas por las aplicaciones de radio para definir una ubicación de forma automática que permita el acceso a determinada información de carácter local. De hecho, en aquellas aplicaciones que permiten la segmentación de contenidos de carácter local, como RNE (iPhone), La SER u Onda Cero (Android) la selección de los mismos suele efectuarse manualmente, a partir de una lista desplegable o deslizable.

Si consideramos la interacción más básica, las posibilidades de activar o desactivar la escucha sin para ello tener que abandonar la interfaz, todas las APP cuentan con dicha posibilidad aunque con matices.

En el caso de aquellas aplicaciones más sencillas, como Hit FM o Kiss FM, la posibilidad de desactivar la escucha está asociada a la opción de silenciar la emisión en directo. En otras radio APP también se puede desactivar la escucha parando la emisión, de modo que al volverla a activar pueda continuarse la escucha en el mismo punto donde se paró.

En este sentido, la posibilidad de desactivar la escucha es más o menos amplia en función de si se trata una APP de radio en directo, o si tiene la posibilidad de seleccionar contenidos a la carta.

Otras posibilidades de intervención de los oyentes-usuarios en el medio para la personalización de su consumo, revierte en cuestiones estéticas como la customización del fondo que permiten la APP de Cadena 40 para Android y la de ABC Radio para iPad; o de navegación, como la posibilidad de de injerir en la organización de la aplicación para iPad de la Radio Galega. En definitiva, se trata de nuevas formas de intervención que las APP brindan a sus usuarios para que personalicen su recepción y creen una radio a su medida. Unas formas de participación en el consumo privado del medio que distan mucho de aprovechar las potencialidades que le brindan los medios convencionales.

\section{Conclusiones}

La radio española ha fijado en los dispositivos portátiles uno de sus ámbitos principales de expansión. En efecto, la mayor parte de las emisoras de radio convencional han puesto a disposición de sus oyentes-usuarios aplicaciones para el acceso optimizado a sus contenidos desde smartphones y/o tablets.

Esta elevada oferta de APP radiofónicas, caracterizada por un iphonocentrismo, es un reflejo de la relevancia que ha adquirido la cultura de la portabilidad en lo que se refiere al consumo de contenidos mediáticos. La necesidad de incorporar a su audiencia a ese usuario conectado ha llevado a las emisoras de radio españolas a abordar la siguiente fase de la radiomorfosis, haciendo de los smarphones las plataformas centrales de su estrategia móvil. 
Sin embargo, estas aplicaciones todavía ofrecen un acceso convencional a los contenidos radiofónicos obviando las posibilidades que brinda Internet y sobre todo los dispositivos móviles para la interacción continua e inmediata de usuarios y productores del medio. Una circunstancia que puede suponer un freno a la fidelización, por parte de las cadenas de radio, de los nativos digitales. En efecto, las plataformas de playlist de música le están ganando terreno al medio radiofónico entre los más jóvenes, acostumbrados a un consumo personalizado de los contenidos de entretenimiento.

El incremento de las potencialidades de los «terminales telefónicos inteligentes» sumado a la portabilidad de sus dimensiones y su penetración, los han refrendado como los receptores idóneos para la radio en movilidad frente otras tipologías de terminales de altas prestaciones. Como señala un estudio de NPD Group (2013), más de la mitad de los propietarios de esta tipología de dispositivos los utilizan o los han utilizado para escuchar música u otro tipo de contenidos sonoros, un $65 \%$ de los cuales han accedido a dichos contenidos a través de servicios de radio online.

Para consolidar su audiencia a través de esta nueva plataforma, las empresas mediáticas deberían plantearse ampliar su oferta de aplicaciones para smartphones Android. Este sistema operativo, el de mayor implantación en el mercado de la telefonía móvil en España, incrementaría el número de oyentes de la radio en movilidad aunque en detrimento de la estandarización de terminales receptores, tanto en las dimensiones de la pantalla como en la memoria y rapidez de gestión de sus contenidos. En este sentido sería interesante que las empresas optasen por simplificar la navegación y el tipo de contenidos de las APP, apostando por sus características diferenciales como plataforma.

Si se atiende a la participación, las posibilidades que prevén las cadenas de radio españolas para sus oyentes-usuarios en movilidad son limitadas respecto a las oportunidades que brinda la radiofonía móvil, tanto desde la perspectiva de la intervención en los contenidos radiofónicos como de personalización del medio para un consumo individual.

En su traspaso a los dispositivos móviles, estas cadenas de radio parecen obviar el nuevo papel del oyente-consumidor, portador de unos dispositivos que le convierten en mucho más que un receptor pasivo. Pese a que tablets y smartphones cuentan con herramientas de grabación y edición audiovisual, su utilización con finalidades comunicativas apenas tiene incidencia en la muestra. De igual modo sucede con la nula integración de redes sociales en las aplicaciones, o con la ausencia de iniciativas que saquen partido a las herramientas de geolocalización de estos dispositivos. La posición dominante de la comunicación radiofónica convencional no puede mantenerse en el futuro, sobre todo en términos de explotación de negocio. La participación del oyente proporciona un conocimiento del mismo que permite orientar la explotación comercial del producto. 
En este contexto, resulta especialmente interesante el aprovechamiento de las posibilidades de geolocalizacion que brindan este tipo de dispositivos móviles; unas potencialidades que permitirían atraer a un mayor número de oyentes de radio local incorporar información ad hoc para usuarios in itinere. La geolocalización podría derivar, inclusive, en nuevas formas de publicidad local que supondrían una interesante fuente de ingresos para esta radio en movilidad.

En lo que se refiere a la intervención de los oyentes-usuarios en los contenidos del medio, las APP analizadas presentan una perspectiva muy convencional de la participación de los oyentes. Fórmulas como la llamada telefónica o la remisión de correos electrónicos exigen minimizar o cerrar la aplicación de radio, y por tanto se trata de modos de participación fuera de esta radio en movilidad. Este tipo de dinámica es consecuencia de una concepción anticuada del proceso y de un talante conservador en la experimentación de nuevas fórmulas posibles de interacción con el usuario. El hecho de que las grandes cadenas comerciales entiendan la participación como algo que se produce oralmente y mediado por el emisor indica que no se ha asumido el cambio en la forma de relacionarse con la audiencia.

Las APP de radio que apenas exploran las posibilidades de los dispositivos portátiles de última generación para establecer nuevas formas de participación de los oyentes-usuarios o dotar de una mayor proyección a algunas de las existentes. En este sentido, los productores de los medios deberían buscar formas de participación más inmediatas, bebiendo con mayor fuerza de las redes sociales como sucede en el caso del medio convencional.

La sencillez técnica que presentan las radio APP también se refleja en el escaso número de aplicaciones que permiten la injerencia del oyente-usuario en la interfaz tanto desde una perspectiva estética como de navegación. La oportunidad de personalización de las radio APP podría incrementar la sensación de selfcommunication del medio especialmente en un dispositivo receptor como el teléfono móvil, cuyo consumo está asociado a un uso personal e intransferible.

En este sentido resulta importante la incorporación de contenidos on demand, para el acceso diacrónico adaptado a las costumbres y necesidades de estos usuarios. Especialmente en lo que se refiere a los podcast, que permiten el consumo de contenidos radiofónicos en momentos en los que el usuario se encuentra offline.

Resulta imprescindible potenciar la capacidad de elección, no solo para el sector de oyentes jóvenes, sino para públicos de mayor edad que pueden actuar al mismo tiempo como consumidores y como prescriptores a través de las redes sociales y las comunidades virtuales. Como a continuación se indica, no se está aprovechando la capacidad del oyente como productor y potenciador de los contenidos del medio en los círculos sociales y económicos en los que se mueve. 
Frente a la renovada concepción de participación en la prensa online -cuya necesidad de contenidos ha llevado a incorporar nuevos cauces de colaboración para aprovechar las posibilidades de un usuario a la vez productor y consumidor- el medio radiofónico se ha quedado anclado en fórmulas convencionales. Si bien la radio hertziana ha logrado reconvertir la participación de los oyentesusuarios a través de las redes sociales, en las radio APP todavía no se ha llevado a cabo dicho salto.

La oferta de aplicaciones de las cadenas de radio españolas ha crecido al margen de las potencialidades de tablets y smarphones y, por ende, desaprovechan las oportunidades de la radiofonía móvil en el marco de la cultura de la portabilidad.

En este sentido se puede hablar de una radiofonía móvil que tiene más de presencia que de esencia porque, si bien existe una oferta de APP de cierta relevancia, ésta no se encuentra adaptada a las nuevas plataformas receptoras; inclusive -tomando como referencia a Cebrián Herreros (2008b) - no se hablaría de radiofonía móvil sino de radio en el móvil: una nueva plataforma de expansión para el mismo producto sonoro.

\section{Bibliografía}

Albarran, Alan B. y Pitts, Gregory G. (2001). Radio broadcasting industry. Boston: Allyn and Bacon.

Alves, Raquel (2003). Rádio no Ciberespaço-Interseção, Adaptação, mudança e Transformação. En: VV.AA. Congresso Brasileiro de Ciências da Comunição. Anais. Belo Horizonte: Intercom. Disponible en: http://www.intercom.org.br/ papers/nacionais/2003/www/pdf/2003_NP06_alves.pdf (10/12/2012).

Asociación para la Investigación de Medios de Comunicación (2012). Resumen general de resultados EGM. Octubre de 2011 a Mayo de 2012. Madrid: AIMC. Disponible en: http://www.aimc.es/-Datos-EGM-Resumen-General-.html $(05 / 11 / 2012)$.

Asociación para la Investigación de Medios de Comunicación (2012). Radio: Tradicional vs. online. Madrid: AIMC. Disponible en: http://www.aimc.es/-LaRadio-Tradicional-vs-Online,196.html (20/9/2012).

Bufarah Junior, Álvaro (2003). Rádio e Internet: desafios e possibilidades. En: VV.AA. XXVII Congresso Brasileiro de Ciências da Comunicação. Disponible en: http://www2.eptic.com.br/sgw/data/bib/artigos/47fe62227cb4c6660b44edae35cff75.pdf (08/11/2012).

Bufarah Junior, Álvaro (2009). O rádio diante das novas tecnologias de comunicação: uma nova forma de gestão. En: E-Com Revista do Departamento de 
Ciências da Comunicação do UNI-BH, Vol. 2, $\mathrm{n}^{0} 4$. Disponible en: http://revistas.unibh.br/ecom/viewarticle.php?id=81 (10/05/2012).

Castells, Manuel, Fernández-Ardévol, Mireia, Linchaun Qiu, Jack y Sey, Araba (2006). Comunicación móvil y sociedad. Una perspectiva global. Barcelona: Ariel-Fundación Telefónica.

Cebrián Herreros, Mariano (2001). La radio en Internet. Disponible en: http:// es.scribd.com/doc/14149453/Mariano-Cebrian-HerrerosLa-radio-en-Internet. $(19 / 7 / 2012)$.

Cebrián Herreros, Mariano (2008a). La radio en Internet. La Crujía: Buenos Aires.

Cebrián Herreros, Mariano (2008b). Radio y convergencia tecnológica en Europa. Expansión de los cibermedios fijos y móviles. En: Ortega Carmona, Leopoldo (comp.). Memorias de la $7^{\circ}$ Bienal Internacional de Radio México. Colonia del Valle: Radio Educación.

Del Bianco, Nelia R. (2011). O futuro do rádio no cenário da convergência frente às incertazas quanto aos modelos de transmissão digital. En: Economia Política das Tecnologias da Informação e da Comunicação, nº 12, 1-19.

Faus, Ángel (2001). Reinventar la radio. En: Chasqui, $\mathrm{n}^{0}$ 74. Disponible en : http://www.comunica.org/chasqui/faus74.htm (19/7/2012).

Fidler, Roger (1997). Mediamorphosis: Understanding New Media. Thousand Oaks: Pine Forge Press.

Fundación Telefónica (2012). La Sociedad de la Información en España. Barcelona: Ariel.

Gallego, Juan Ignacio (2010). Podcasting: Nuevos modelos de distribución para los contenidos sonoros. Barcelona: UOC.

González Conde, María Julia y Salgado Santamaría, Carmen (2009). Redes de participación e intercambios comunicativos en la radio pública. En: Revista Comunicar, $\mathrm{n}^{\circ} 33,45-54$.

González Conde, María Julia (2010). La ciberradio. Nueva alternativa de futuro para la radio. En: Revista de estudios de juventud, n ${ }^{0}$ 88, 51-62.

Herrera Damas, Susana (2004). La participación de los oyentes en los programas e radio, ¿un género radiofónico? En: Revista de Comunicación, n ${ }^{0}$ 3, 7-19.

Jenkins, Henry (2008). Cultura da convergência. São Paulo: Aleph.

Johnson, Laurence F., Adams, Samantha, y Cummins, Michele (2012). New Media Consortium Horizon Report: 2012 K-12 Edition. Austin: The New Media. Disponible en: http://www.nmc.org/publications/2012-horizon-report-k12 (2/03/2013). 
Kischinhesky, Marcelo (2009). Cultura da portabilidade - Novos usos do rádio e sociabilidades em mídia sonora. En: Observatorio $\left(O B S^{*}\right)$ Journal, n ${ }^{0} 8,223$ 238.

Merayo, Arturo (2000). Identidad, sentido y uso de la radio educativa. En: Pastor, Gerardo; Pinto, $\mathrm{M}^{\mathrm{a}}$ Rosa y Echeverri, Ana Lucía (orgs.). Actas del III Congreso Internacional Cultura y Medios de Comunicación. Salamanca: Universidad Pontificia de Salamanca.

Moreno, Elsa; Martínez-Costa, Pilar y Amoedo, Avelino (2009). Radio and the Web: Communication Communication Strategies of Spanish Radio Networks on the Web (2006-2008). En: Observatorio (OBS*) Journal, n ${ }^{\circ} 10,121-137$.

NPD Group (2013). Half of tablet and smartphone users are using these devices to listen to music. Disponible en: https://www.npd.com/ (15/3/2013).

Nyre, Lars y Ala-Fossi, Marko (2008). The next generation platform: Comparing audience registration and participation in digital sound media. En: Journal of Radio \& Audio Media, Vol. 15, nº $1,41-58$.

Ortiz Sobrino, Miguel Ángel (2012). Radio y post-radio en España: una cohabitación necesaria y posible. En: Área Abierta, no ${ }^{\circ} 32$, 1-16. Disponible en: http:// revistas.ucm.es/index.php/ARAB/article/view/39637 (11/12/2012).

Pacheco, Alex (s/d). A estrutura da webrádio. Biblioteca Online de Ciencias da Comunicaçao. Disponible en: http://www.bocc.ubi.pt (11/12/2012).

Padley, Brittany (2012). Websites vs. Mobile app: a content analysis of tampa bay's news. Tesis para adquirir el grado de Máster en Artes. Departmento de Journalism \& Media Studies. University of South Florida. Saint Petersburg. Disponible en: http://hdl.handle.net/10806/4604 (11/01/2013).

Prata, Nair (2008). Webradio: novos géneros, novas formas de interacção. Tesis de doctorado em Estudios Lingüísticos. Faculdade de Letras. Universidade Federal de Minas Gerais. Belo Horizonte. Disponible en: http://www.dominiopublico.gov.br/pesquisa/DetalheObraForm.do? select_action=\&co_obra=101837 $(10 / 09 / 2012)$

Priestman, Chris (2002). Web Radio: Radio prodution for Internet streaming. Oxford: Focal Press.

Rivadeneyra, Carlos (2008). Pugna, convergencia y diversidad de la radio latinoamericana en el escenario digital. En: Ortega Carmona, Leopoldo (comp.). Memorias de la $7^{\circ}$ Bienal Internacional de Radio México. Colonia del Valle: Radio Educación.

Tolson, Andrew (2006). Media talk. Spoken discourse on TV and radio. Edinburgo: Edinburg University Press. 
Vacas, Francisco (2007). Teléfonos móviles. La nueva ventana para la comunicación integral. Madrid: Creaciones Copyright.

Vieira, Jorge; Cardoso, Gustavo y Medoça, Sandro (2010). Os Novos Camiños da Radio. Radiomorphosis. Tendências e Prospectivas. Lisboa: Obercom. Disponible en: http://www.obercom.pt/client/?newsId=428\&fileName=estudo_tendencias_radio.pdf (23/12/2012).

\section{Referencia de este artículo}

Piñeiro-Otero, Teresa y Videla Rodríguez, Juan (2013). La participación de los oyentes en las radio APP españolas. Prácticas convencionales en la era de la portabilidad. En: adComunica. Revista Científica de Estrategias, Tendencias e Innovación en Comunicación, $\mathrm{n}^{\circ} 5$. Castellón: Asociación para el Desarrollo de la Comunicación adComunica, Universidad Complutense de Madrid y Universitat Jaume I, 67-89. DOI: http://dx.doi.org/10.6035/2174-0992.2013.5.6 